American Journal of Economics and Business Administration 2 (3): 247-252, 2010

ISSN 1945-5488

(C) 2010 Science Publications

\title{
Seller Concentration in the Grain Milling Industry
}

\author{
${ }^{1}$ Martin Charumbira and ${ }^{2}$ Tafirenyika Sunde \\ ${ }^{1}$ Midlands State University, Zimbabwe \\ ${ }^{2}$ Department of Economics, Polytechnic of Namibia, \\ School of Business and Management, P.O. Box 13388, Windhoek, Namibia
}

\begin{abstract}
Problem statement: The main purpose of the study was to explore the levels of concentration in Zimbabwe's grain-milling industry during period 1985-2005. The study could not be extended to periods after 2005 because the situation in the country had become economically chaotic. Approach: The methodology adopted involved the calculation of the concentration indices such as the Herfindall-Hirschman index, Hannah and Kay index, the Entropy index and the Four-Firm Concentration ratio. Results: The study revealed that liberalisation of the industry reduced seller concentration levels. The response to deregulation in this particular sector confirms the theoretical expectation that liberalisation promotes competition and reduces market power of existing firms, which is also consistent with the world-wide trends. Conclusion: The policies adopted at the inception of Economic Structural Adjustment Programmed (ESAP) should be pursued more vigorously to create a manufacturing base which is open to competition and which is insulated from adverse effects of possible manipulation by a few large firms. Policy should be aimed at maintaining affordability of the basic commodities to the consumers as well as ensuring viability to the manufacturers. With high levels of industrial concentration, producers are able to operate at a higher-cost system without losing market share, but this is to the detriment of the consumers.
\end{abstract}

Key words: Concentration, concentration ratio, oligopoly, grain milling, liberalisation, ESAP

\section{INTRODUCTION}

The policies that were operative before ESAP ensured that there were no major price swings as regards basic foodstuffs. This was because the government gazetted the prices of basic foodstuffs such as bread, salt, sugar and cooking oil among others. Manufacturers who deviated from the set prices risked legal action. The effectiveness of price controls seemed to have been aided by the concurrent subsidies, which were paid directly to the producers. Such techniques of price management are counter liberalization, but the authorities seemed to trust. The pre-1991 price management policy was therefore characterized by 'suppressed inflation'. When price controls were lifted in 1991 and subsidies gradually removed, the basic foodstuffs, that had previously benefited most from those policies, experienced the sharpest price rises. This was further exacerbated by the fact that such commodities were gradually more supply-constrained than other commodities.
Shortages of certain food stuffs and other commodities, like building materials were a longstanding problem that demanded policy intervention. A prime example of such supply inadequacies was the cement shortage that haunted construction works in the country, most markedly between 1996 and 1998 and the period after 2003. The only two established cement producers in the country United Portland Cement and Circle Cement Limited could not produce enough to meet the prevailing demand. It is therefore important to investigate and establish a link if any exists between low production levels and declining profitability in the industry.

Imperfect market structures and the potential profiteering that goes with them are a common characteristic of most emerging markets, especially those that have experienced years of price controls. The grain milling industry was traditionally comprised of three large-scale producers (National Foods Limited, Blue Ribbon Foods Limited and Victoria Foods). The small-scale millers and grinding mills are the ones that competed with these big companies and as a result

Corresponding Author: Tafirenyika Sunde, Department of Economics, Polytechnic of Namibia, School of Business and Management, P.O. Box 13388, Windhoek, Namibia Tel: +264-61-2072406 Fax: +264-61-207 2442 
these big companies dictated the pace in the industry. As a result of liberalization, the Millers' Association claimed that the market share of the large-scale millers declined from $70 \%$ in 1994 to $25 \%$ in 1998, implying that there was no scope for the Millers' Association to unduly influence the selling price against the dictates of market forces (Sleuwaegen and Dehandschutter, 1986). The government had in certain instances cited the uniformity of prices of mealie meal produced by the three major millers as evidence to entrench its position that the millers were acting like a price-setting cartel. The millers in turn maintained that they all faced the same GMB selling price and faced similar costs of electricity, wages and salaries, interest on working capital and meal packing costs. They argued that $95 \%$ of their costs are common. The uniformity of their prices was therefore an outcome of the similarity of their cost structures.

The same viability threat which beset the maize milling companies also haunted the flour millers who had to cope with increased input costs amid government reluctance to allow concomitant price adjustments. Since the onset of liberalization in 1991, the number of flour millers increased from three to seven. The flour millers were even in a worse position due to the fact that they were much more reliant on imported wheat than are the maize millers. Flour millers needed 400000 tonnes of wheat per annum for flour production. Of this, only $65 \%$ was produced locally. This meant that when the local currency depreciated, wheat prices rose substantially.

The manufacturing sector of Zimbabwe was one of the most extensively regulated sectors in the Zimbabwean economy. Prices of the basic commodities and entry into certain sub-sectors were restricted. The industries such as telecommunication, broadcasting and railway transport services were for long time the domain of government-mandated enterprises. The marketing of agricultural produce and minerals had until recently been confined to the Marketing Boards, which were parastatal organs. For example, farmers were required to sell all cereals through the Grain Marketing Board. This meant that GMB had dominance and control over the distribution chain (Sleuwaegen and Dehandschutter, 1986).

Since the regulations on crop marketing changed in 1993, the millers were allowed to exercise autonomy in sourcing their inputs directly from the producers (farmers). The millers, however, were still heavily reliant on the GMB since it was the only reliable perennial supplier. Government regulations on the grain-mill products seemed to be premised on the fact that such products are 'basic goods' which should be accessible to the majority of the people. Although competition in the industry was not precluded altogether, market responsiveness was very weak with price hikes being authorized by the government even during the liberalisation era. It is generally agreed that government interference on the manufacturing sector imposes considerable costs upon society. Controls were blamed for the mediocre quality of commodity delivery systems and the accompanying shortages of goods and services.

Price controls, while very effective in preventing sharp price hikes, are detrimental to the producers and could stifle production or even result in outright closure of some firms. If the controls on prices are so acute as to deny some firms the opportunity to break-even, then the outcome could be shortages, a situation much more undesirable than what the controls intended to prevent. The policy guiding principles on industrial structure point towards a great deal of reliance on market forces to shape prices, relegating the role of the authorities to regulating only those firms which attempt to foreclose the industry from entrants for anti-competitive reasons. Producers of certain food commodities were often prevented by the government from increasing their prices with the authorities arguing that such manufacturers were profiteering at the expense of consumer welfare.

The research seeks:

- To assess if firms in the grain milling industry possess sufficient market power to enable them in their individual and collective capacities to influence the price of products

- To establish if the firms in the grain milling industry operate in cartel fashion to the detriment of consumers

The profitability of firms in the milling industry is firmly dependant on the degree of industrial concentration. The nature, causes and more importantly the consequences of market concentration have become sensitive topics in Zimbabwe. In Zimbabwe no official measures of concentration are published by the Central Statistical Office (CSO) or by other government departments.

Empirical literature: Kessides (1990) provides evidence that advertising has actually facilitated entry into the US manufacturing sector, contrary to the widely held view that it acts as a deterrent to entry. His findings tend discredit the 'advertising as persuasion' view while lending strong support to the 'advertising as information' perspective. Grabowski and Vernon 
(1992) in their study of the generic pharmaceuticals in the USA found that high advertising-sales ratio did not act as an effective entry barrier. This implies that the structure of the market they studied was independent of the advertising intensity. Some studies conceive advertising as a hindrance to entry. Leach (2006) suggest that the industries with high advertising-sales ratios in the USA have low entry rates. Rizzo and Zeckhauser (1990) find a similar result for the study of physician services in the USA. Kaplinsky and Manning (1998) trace the origins of producer concentration in the South African furniture industry to a spate of mergers and acquisitions of furniture manufacturing companies, which took place in small establishments and firms. They note that the rise to dominance of AFCOL (furniture firm in SA) in the South African furniture industry was due to a series of mergers and acquisitions that saw it develop to conglomerate level, with $35 \%$ market share in 1998. Concentration levels in the South African economy are considered quite high. An unclassified study by the Mouton Commission was the first to find out that levels of industrial concentration in South Africa were too high. The commission classified 9 of the 30 industry main groups as 'highly concentrated' and 6 as 'concentrated' in 1972. At a more disaggregated 5-digit level of industrial classification, the commission identified up to $75 \%$ of industries as concentrated or highly concentrated and as few as $7.7 \%$ as unconcentrated. On the international scene they found average concentration levels in South African manufacturing to be higher than those in France, Italy, West Germany and Britain. The situation could well have significantly changed since the ESAP when the imports from South Africa and other countries were allowed into the country notes that the concentration levels in Canada's manufacturing sector were stable since the $1970 \mathrm{~s}$, with a mere $1.05 \%$ reduction in concentration recorded. The Canadian Department of Consumer and Corporate Affairs classifies market structures on the basis of the 4-firm concentration ratio using the following scheme:

$(0-0.249)$

slightly concentrated oligopoly

(0.5-0.749) moderately concentrated

Oligopoly

(0.75-1.00) highly concentrated oligopoly

Baldwin and Gorecki (1992) in a study of Zimbabwe's manufacturing sector for the period 197086 used a 4-firm seller concentration ratio to analyze various industries. He found that three quarters of the 53 industries he studied could be classified as highly concentrated oligopolies. Six can be classified as moderately concentrated with ratios ranging from 0.5 0.7 . Five industries had ratios between 0.25 and 0.49 . Only one (clothing industry) had a ratio below 0.25 . The clothing industry was the least concentrated in (Baldwin and Gorecki, 1992) findings. After regressing markups on concentration, he concludes that there is no relationship between market power and profitability in the Zimbabwean manufacturing sector.

Braunerhjelm and Fors (1995) assessed the level of competition in Zimbabwe's manufacturing industry at sub-sector level. The highest concentration was found in the non-metal minerals sub-sector. This sector produces products like glass and cement, which are characterized by large-scale operations. This makes entry difficult, making the industry a domain of few already established firms. The sub-sector has a 4-firm concentration ratio of $91 \%$ and a Herfindahll index of 0.26 . Concentration in this sub-sector is the highest using either measure. The Chemicals sub-sector has the lowest 4-firm concentration ratio of $32 \%$.

Braunerhjelm and Fors (1995) make an attempt to differentiate among the sub-sectors' overall exposure to competition, taking into account both domestic and foreign competition. Foreign competition is highest for the Transport and Equipment sub-sector and lowest for the Clothing and Footwear sub-sector. Combining both domestic and foreign competition, the most concentrated sub-sectors are Chemicals and Metals and Metal products.

The low import competition in the Clothing and Footwear industry in the study by (Braunerhjelm and Fors, 1995) can be explained by the ban on imports of such commodities, which was effected during the period of study. They determine each sector's exposure to foreign competition by measuring the level of import penetration in sub-sector $\mathrm{j}$ as follows:

$$
\frac{M_{j}}{D_{j}}=\frac{M_{j}}{\left(G_{j}-X_{j}+M_{j}\right)}
$$

Where:

$\mathrm{M}_{\mathrm{j}} \quad=$ Refers to Zimbabwe's imports of products classified under sub-sector $\mathrm{j}$

$\mathrm{G}_{\mathrm{j}}$ and $\mathrm{X}_{\mathrm{j}}=$ The sub-sector's own gross output and exports, respectively

$\mathrm{D}_{\mathrm{j}} \quad=$ The total consumption by the domestic market

The competition in the Zimbabwean grain milling sector was predominantly domestic. Although (Braunerhjelm and Fors, 1995) found low levels of 
competition in the Textiles sub-sector, the circumstances had changed significantly since then due to the liberalization policies adopted by the government could change this position, as foreign products are likely to find easier way into the local market, thus further lowering the import-adjusted concentration levels. This is particularly noticeable in the Textile subsector where a number of local firms were driven out of business by the influx of cheap imports.

\section{MATERIALS AND METHODS}

Concentration is perhaps the most prominent aspect of market structure. Comprehensive analysis of concentration requires that there is a summary index that condenses the size distribution of firms in an industry to a single number. However the use of a onedimensional index to describe a multi-dimensional phenomenon involves considerable loss of information, some of which may be valuable.

In the following sub-sections we look at some measures of concentration, namely the Concentration Ratio (CR), the Herfindahl-Hirshman (HH) Index, the Hannah and Kay (HK) Index and the Entropy (E) Index.

Concentration Ratio $\left(\mathbf{C R}_{\mathbf{r}}\right)$ : This measure shows the proportion of the industry's output accounted for by $r$ largest firms:

$$
\mathrm{CR}_{\mathrm{r}}=\sum \mathrm{S}_{\mathrm{i}}
$$

Where:

$\mathrm{S}_{\mathrm{i}}=$ The market share of firm $\mathrm{i}$

The ratio shows the joint market share of the largest $r$ firms in manufacturing industry. Once the aggregate data of the manufacturing industry and that of the $r$ largest firms is accessible, the ratio can be determined, avoiding the complications of dealing with the individual accounts of the fringe of numerous small firms in the industry.

Ferguson (1994) criticizes the use of the concentration ratio with firm level data for two main deficiencies: First it ignores the relative size variation across the $r$ largest firms. As a result the same concentration ratio could describe a market where there are $r$ similarly sized firms or a situation where one of the $r$ firms dominates. Secondly, it neglects all except the largest $r$ firms. This makes it flawed because it gives the impression that the two markets with identical shares held by the $r$ largest firms have identical concentration ratios even though one market contains more firms in total and is likely to be more competitive.
Herfindall-Hirschman Index (HH): The HH index is the sum of squares of the market shares of each of the firms in the industry:

$$
\mathrm{HH}=\sum \mathrm{S}_{\mathrm{i}}^{2}
$$

where, $\mathrm{n}$ is the total number of firms.

In an ideal situation where all $\mathrm{n}$ firms are of equal size, then $H H=1 / n$. The strength of the $H H$ index lies in its ability to combine information on both the number and the size distribution of firms. For this reason Martin (1993) believes it is the preferred measure. However its data requirements are immense as its calculation of would demand firm level data for all individual firms in the industry. Ferguson (1994) notes that the squaring of market shares gives greater weight to larger firms. In practice, many different distributions could give the same value of the $\mathrm{HH}$ index.

\section{Hannah and Kay Index (HK):}

$$
\mathrm{HK}=\sum \mathrm{S}_{\mathrm{i}}^{\alpha}
$$

where, $\alpha$ is an elasticity parameter, whose value shows the weight, given to larger firms relative to smaller ones. (Where $\alpha=2, H H=H K$ ). The choice of $\alpha$ is an arbitrary process, although Hannah and Kay the cooriginators of the index suggest that $\alpha$ should be in the range 0.6-2.5 for sensible results to obtain. Their suggestion is merely based on computer simulations. The choice of $\alpha$ shows how much weight one wants to attach to the size distribution of firms relative to their number. Davies et al. (1992) suggest that in the aggregation of production functions across plants $\alpha$ could be determined by the degree of scale economies. The HK is often criticised for the apparently arbitrary and inconclusive nature of the choice of $\alpha$.

Entropy index (E): When calculating the entropy index, market shares of firms are weighted by the natural log of their reciprocals:

$$
\mathrm{E}=\sum \mathrm{S}_{\mathrm{i}} \ln \left(1 / \mathrm{S}_{\mathrm{i}}\right)
$$

If all firms are of equal size, $S_{i}=1 / \mathrm{N}$, but where they are very much unequal in size the entropy index tends to zero. Low values of $E$ indicate high concentration.

The entropy index has been criticized for being more sensitive to the number of firms than most indices (Davies et al., 1992). Davies et al. (1992) however admit to the superiority of the index over the $\mathrm{HH}$ in one 
respect: that of decomposition. This is a statistical property that ensures that the index can be decomposed into within and between-group components. This is quite important due to the fact that most industries are constituted by a number of sub-sectors and it might be necessary to know how much each contributes to the whole and how concentration compares between constituent parts. Davies et al. (1992) conclude that $\mathrm{E}$ is preferable in descriptive statistical studies, but is less popular when testing behavioral relationships generated by economic theory.

Sleuwaegen and Dehandschutter (1986) and Martin (1993) analyze some of the implications of the relationship between the Herfindall-Hirschman index and the $r$ firm concentration ratio within the context of empirical models dealing with price-cost margins and concentration. They find that the two measures may provide empirically different information to assess industry performance. The HK index has the advantages of generality and flexibility, but as Davies et al. (1992) observe, the index has remained uncommon and has not been widely used due to the considerable data and time input requirement. Despite the fact that it is the least sophisticated of the alternatives, the concentration ratio has remained the most commonly employed concentration measure. It is the measure published in the Census of Production in most countries. Variations exist across countries on the typical value of $r$. the UK Census reports the 5-firm seller concentration ratio and the US Census the 4- and 8 -firm ratios. Neither of them publishes the aggregate concentration ratios.

\section{RESULTS}

The results summarize the findings on the concentration levels in the Grain Milling Industry of Zimbabwe.

The trend reflected by the Four-Firm Concentration ratio points to a rapidly declining seller concentration in the post-liberalization era starting in 1995. This is consistent with the predictions of theoretical and empirical literature. Table 1 shows that by 2005, the four largest firms in the Grain Milling industry had a market share of only 28\%, compared to 0.84 for 1985 . Table 1, summarises all the results of the study by showing all the concentration indices that we got by using the various measures of concentration.

Table 1: The concentration indices in the grain milling sector

\begin{tabular}{lllll}
\hline Year & HH & HK & CR4 & E \\
\hline 1985 & 0.32 & 0.48 & 0.84 & 0.64 \\
1995 & 0.27 & 0.36 & 0.72 & 0.62 \\
2005 & 0.18 & 0.31 & 0.28 & 0.77 \\
\hline
\end{tabular}

\section{DISCUSSION}

Using the market classification applied by the Canadian Department of Consumer and Corporate Affairs, we can conclude that the Grain Milling sector in Zimbabwe was within the range of a slightly concentrated oligopoly. There is little scope in such a market for any individual firm, without seeking the concurrence of others, to manipulate the prices unless there are of course some economy-wide bottlenecks and location advantages allowing it to do so. Both the $\mathrm{HH}$ and the HK also declined over the liberalization era, thus providing evidence which is complementary to the CR-4. The largest value that the HH can assume is 1, in which case the industry is a monopoly, with the only firm in the industry possessing absolute market power. The Entropy index is largely consistent with other indices, except for year 1995, where it takes a value of 0.62 , which would suggest that concentration had increased. In the extreme case of monopoly the E Index takes a value of 0 . There is almost compelling evidence to the effect that liberalization opened up the sector to new players whose overall contribution to the industry output is quite significant.

\section{CONCLUSION}

The results presented above can be a useful tool in the formulation of competition policy. The measures calculated in this study show how much production is concentrated in the hands large firms. If we presume that the Structure-Conduct-Performance (S-C-P) paradigm is valid then the possibility that market power could be abused by firms who want to profiteer, is a cause of concern to any policy-makers. Industries with very high price-cost margins should therefore be scrutinized for possible abuse of market power. Rather than trying to regulate the conduct of firms, in particular their pricing policies, the government should focus on the structure of the market that generates such behavior. Any attempt to interfere with the decisions of firms with regards to the prices which, is counterliberalisation, is detrimental to manufacturers and the consumers in the long-run because production viability is negatively affected and shortages will be experienced. The policies adopted at the inception of ESAP should be pursued more vigorously to create a manufacturing base which is open to competition and which is insulated from adverse effects of possible manipulation by few large firms.

Policy should be aimed at maintaining affordability of the basic commodities to the consumers as well as ensuring viability to the manufacturers. With high 
levels of industrial concentration, producers are able to operate at a higher-cost system without losing market share, but to the detriment of the consumers. The literature confirms a strong market share-profitability link. The authorities are expected to emphasize competition policies in the manufacturing sector rather than to revert to subsidization and price controls which were viewed as politically expedient solutions in the 1980s but which are unpopular with the manufacturers and the Breton woods institutions.

\section{REFERENCES}

Baldwin, J.R. and P.K. Gorecki, 1992. Development of financial markets and the size distribution of manufacturing establishments: International comparisons. World Dev., 20: 1489-1499. DOI: 10.1016/0305-750X (92) 90069-8

Braunerhjelm, P. and G. Fors, 1995. The Zimbabwean manufacturing sector: Current status and the future developments. Industrial Institute of Economic Society and Research, Sweden.

Davies, S., B. Lyons, H. Dixon and P. Geroski, 1992. Economics of Industrial Organization. 2nd Edn., Longman London and, New York, ISBN: 0-58229567-X, pp: 248.

Ferguson, P., 1994. Industrial Economics: Issues and Perspectives. 2nd Edn., MacMillan, London, ISBN: 9780409100440, pp: 420.
Grabowski, H. and J. Vernon, 1992. Brand Loyalty, entry and price competition in the pharmaceuticals after the 1994 drug act. J. Law Econ. Ind., Metapress, 35: 133-163. DOI: 10.1111/j.14309134.1997.00075.x

Kaplinsky, R. and C. Manning, 1998. Concentration policy and the role of the small and mediumsized enterprises in South Africa. J. Dev. Stud., 35: 34-35. DOI: 10.1016/S0305-750X (99)00024-8

Kessides, I.N., 1990. Towards a testable model of entry: A study of the US manufacturing industries. Econ., Econ., New Ser., 57: 219-238 DOI: 10.1016/S0167-7187(97)00072-6

Leach, D.F., 2006. Absolute versus relative concentration in the manufacturing industry, 19721985. South Afr. J. Econ., 60: 229-238. DOI: 10.1111/j.1813-6982.1977.tb00530.x

Martin, S., 1993. Advanced Industrial Economics. 2nd Edn., Blackwell Publishers, USA., ISBN: 10: 063117981X, pp: 552.

Rizzo, J. and R. Zeckhauser, 1990. Advertising and entry: The case of physician services. J. Polit. Econ., 98: 476-500. DOI: 10.1016/01677187(95)00498-X

Sleuwaegen, L.E. and W.V. Dehandschutter, 1986. The herfindahl index and concentration ratios revisited. Antit. Bull., 34: 625-640. 